\title{
Relation of Rat Brain Acetylcholine Levels to Duration of Self-stimulation and Escape Behavior ${ }^{1}$
}

\author{
EDWARD F. DOMINO, ANN E. WILSON AND MARIANNE E. OLDS ${ }^{2}$ \\ Michigan Neuropharmacology Research Program, Department of Pharmacology \\ The University of Michigan, Ann Arbor, Michigan 48104 \\ and \\ Lafayette Clinic, Detroit, Michigan 48207
}

(Received 27 June 1974)

\begin{abstract}
DOMINO, E. F., A. E. WILSON AND M. E. OLDS. Relation of rat brain acetylcholine levels to duration of self-stimulation and escape behavior. PHARMAC. BIOCHEM. BEHAV. 3(1) 103-107, 1975. - Total brain acetylcholine (ACh) was assayed in groups of animals after various periods of operant responding maintained by electrical stimulation of the lateral posterior hypothalamus or of escape behavior induced by electrical stimulation of the midbrain tegmentum. Different groups of trained rats were placed in identical Skinner boxes for periods of 1 to $24 \mathrm{hr}$. The following groups were studied: controls, self-stimulators receiving electrical stimulation, escapers from brain stimulation or peripherally applied aversive stimulation, self-stimulators not receiving electrical stimulation prior to decapitation, tubocurarine-paralyzed respired rats with electrodes in the posterior-lateral hypothalamus not receiving stimulation, and a group of tubocurarine-paralyzed, respired rats receiving electrical stimulation automatically. It was found that brain stimulation decreased total brain ACh, regardless of whether the stimulation was positive, as during self-stimulation behavior, or negative, as during escape behavior. Animals that received positive stimulation while being paralyzed showed similar decreases in total brain ACh, but the change in $\mathrm{ACh}$ was smaller. No changes occurred in animals that were paralyzed that received no electrical stimulation. It is concluded that brain usage produced by electrical stimulation of discrete functional pathways causes a reduction of total $\mathrm{ACh}$, but this is unrelated to the specific motivational properties of the electrical stimuli.
\end{abstract}

Acetylcholine Self-stimulation behavior Escape behavior

THERE is evidence that brain acetylcholine ( $\mathrm{ACh})$ is involved in various physiological functions such as arousal, REM sleep, and "no-go" behavior [4]. A reduction of behavior maintained by both positive and negative reinforcement is related to an elevation of brain ACh $[5,11$, $13,21,25,28,29]$. On the basis of these findings, the view has evolved that $\mathrm{ACh}$ influences, in a nonspecific way, a number of behaviors. This seems to be the case, especially so far as self-stimulation behavior is concerned. Some sort of relationship exists between $\mathrm{ACh}$ and self-stimulation behavior, although other transmitters, such as the catecholamines, also play an important role in this system. For example, self-stimulation behavior is more sensitive to depression by cholinergic agonists than escape behavior is from brain stimulation in the central gray region. The role of $\mathrm{ACh}$ in regard to behavior in general is still unclear and, moreover, the possibility exists that self-stimulation behavior is particularly sensitive to changes in levels of brain $\mathrm{ACh}$. It seemed worthwhile to continue the investigation of the function of $\mathrm{ACh}$ in behavior maintained by brain reward to gain additional insight into the relation between brain chemistry and behavior.

It is well known that brain ACh can vary with the physiological state of the organism. For example, sedatives elevate brain $\mathrm{ACh}$, while stimulants and convulsants, including electroshock, lower it $[1,10,22]$. In addition, there is a marked diurnal variation in brain $\mathrm{ACh}$ related to motor activity $[9,12,16]$.

We have previously reported that brain $\mathrm{ACh}$ is slightly decreased by handling and injection of naive animals. It is also reduced by self-stimulation and escape behavior from brain shock lasting for a period of $30 \mathrm{~min}$ prior to decapitation [6]. Further reduction occurred when selfstimulating animals were pretreated with d-amphetamine,

\footnotetext{
${ }_{1}^{1}$ Supported in part by NIMH Grant NH-11846 (to EFD) and MH-11627 (to JO).

${ }^{2}$ Present address: Division of Biology, California Institute of Technology, Pasadena, California 91109.
} 
scopolamine, chlordiazepoxide, and diphenylhydantoin The potentiation of the stimulation-induced reduction was small. However, this could have been related to the fact that the period of self-stimulation lasted only $30 \mathrm{~min}$. It seemed possible that longer periods of responding would reveal much larger decreases if such prolonged usage depleted brain stores of $\mathrm{ACh}$ and synthesis would not be able to keep up with utilization. The results reported here were obtained in experiments designed to test this possibility. The present report summarizes data which indicate that prolonged self-stimulation and escape behavior for brain shock reduce brain $\mathrm{ACh}$. Furthermore, the decreases seem to be a function of the amount of stimulation received rather than of the site where electrical stimulation was applied, or of the motivational characteristic of the stimuli.

\section{METHOD}

\section{Animals}

The experiments were conducted on a total of 220 male albino Holtzman rats weighing $300-350 \mathrm{~g}$. Throughout the course of the experiments, the rats were maintained on an ad lib feeding schedule and were housed in individual cages.

\section{Surgery}

One pair of electrodes (twisted stainless steel wires, $250 \mu$ dia) was implanted in each animal. The rat atlas by Krieg [15] was used to determine stereotaxic coordinates. To obtain a group of self-stimulators, the electrodes were aimed at the posterior lateral hypothalamus. For this group, the coordinates were $5 \mathrm{~mm}$ posterior from bregma, $1.5 \mathrm{~mm}$ lateral, and $8 \mathrm{~mm}$ in depth from the top of the skull. To obtain a group of animals that escaped from aversive brain stimulation, the electrodes were aimed at the central gray region, and the coordinates were $8 \mathrm{~mm}$ posterior from bregma, $1 \mathrm{~mm}$ lateral to the midline, and $5 \mathrm{~mm}$ in depth from the top of the skull. Surgery was performed under sodium pentobarbital anesthesia, $50 \mathrm{mg} / \mathrm{kg}$, i.p. The details of the surgical procedures have been described by Olds and Olds $[20]$.

\section{Procedures}

After several days of recovery from surgery, the animals were trained in Skinner boxes to depress a metal lever, which in self-stimulation tests caused the application of a 1/4 sec train of stimulation and in escape tests caused the abatement for $6 \mathrm{sec}$ of a repetitive series of $1 / 2 \mathrm{sec}$ trains applied at one per sec. The stimuli were $60 \mathrm{~Hz}$ sine waves delivered in the first test to the posterior lateral hypothalamic region, and in the second test to the central gray region of the tegmentum. For self-stimulation, a current ranging between $40-60 \mu \mathrm{A}$ was selected because this intensity produced optimal rates of responding. Further details have been given elsewhere $[5,6,18,19]$. In preliminary sessions to determine stimulation levels for escape tests, current was adjusted repeatedly (in $5 \mu \mathrm{A}$ steps) and then was set at a level that optimized escape behavior, or at $40 \mu \mathrm{A}$, whichever was the lower of the two. In selfstimulation tests, only rats with response rates of 300 to 1000 in an $8 \mathrm{~min}$ period were used. In escape tests, the rats had to press the pedal often enough to escape successfully from a minimum of 130 aversive stimuli in an $8 \mathrm{~min}$ period.

The escape test has been described previously $[19,27]$. This method differs from that of Sidman [24] in that responses made in the absence of shock did not postpone the subsequent shock. The animals remained motionless during the intervals between stimulation and then responded quickly, but only after one or two trains were applied. Thus, one or more stimuli were needed to function as cues for the initiation of responding, which postponed the aversive stimuli for $6 \mathrm{sec}$

At least 10 daily sessions of $2 \mathrm{hr}$ each were given for training before the animals were categorized on the above criterion as suitable for the experiments. During the experimental period, each rat worked in a standard session at a fixed time each weekday. One group of self-stimulating rats was paralyzed with $10 \mathrm{mg} / \mathrm{kg}$ of tubocurarine and placed on artificial respiration. These animals were then electrically stimulated at a rate of $100 \mathrm{stimuli} / \mathrm{min}$ at the same current at which they normally responded, the rate being approximately the same as they would normally maintain during a self-stimulation session.

\section{Brain Assays}

Animals used in these assays were sacrificed by decapitation between 10-11:00 a.m. Each brain was quickly excised, and the cerebellum dissected away.

The brain extracts were prepared by the acid-alcohol method $[3,26]$. The ACh-like activity of the extracts was bioassayed on the isolated frog (Rana pipiens) rectus abdominus muscle preparation. As suggested by Feldberg [8], ACh standards were prepared in alkali-inactivated extracts to allow for the presence of sensitizing factors in the brain tissue.

\section{Analysis of Data}

Response rates were calculated for the total period as responses/min. Mean \pm S.E. were computed for each group of animals in a given experiment and were subjected to statistical analysis using the Student's $t$ test.

\section{RESULTS}

The mean \pm S.E. for total brain $\mathrm{ACh}$ and behavioral response rates for various groups of animals are given in Fig. 1. The control animals, which had brain hypothalamic electrodes, were habituated for a minimum of $1 \mathrm{hr}$ per day for several weeks in the test chamber before the test period on the day of decapitation. These animals were not stimulated during the habituation nor during the experimental session. By contrast, the group of selfstimulators were stimulated during many training sessions and also self-stimulated during the experimental session before decapitation. As can be seen in Fig. 1, total brain ACh decreased as a function of the duration of the experimental session in the group of self-stimulators; that is to say, as a function of the duration of the period when stimulation was received. Thus, the largest decrease occurred in the group of animals allowed to self-stimulate for a $24 \mathrm{hr}$ period. As might be expected, the rate of responding during this period was not uniform from interval to interval and, furthermore, responding decreased toward the end of the session. An additional feature of the pattern of behavior during such a prolonged period was a slight increase in the rate of responding during the $12 \mathrm{hr}$ interval. This was possibly related to the circadian properties attending self-stimulation behavior, and would explain the increase in the rate of responding after $12 \mathrm{hr}$ 
TABLE 1

EFFECTS OF ESCAPE BEHAVIOR AND CURRENT INTENSITY ON RAT BRAIN ACh

\begin{tabular}{lccccc}
\hline $\begin{array}{l}\text { Type of } \\
\text { Procedure }\end{array}$ & $\mathrm{N} \dagger$ & $\begin{array}{c}\text { Mean } \pm \text { S.E. } \\
(\mathrm{nmol} / \mathrm{g})\end{array}$ & $\mathrm{N} \dagger$ & $\begin{array}{c}\text { Controls } \\
\text { Mean } \pm \text { S.E. } \\
(\mathrm{nmol} / \mathrm{g})\end{array}$ & $p^{*}$ \\
\hline $3 \mathrm{hr}$ escape & 14 & $13.9 \pm 0.8$ & 5 & $17.8 \pm 1.9$ & $<0.01$ \\
$24 \mathrm{hr}$ escape & 6 & $11.3 \pm 1.9$ & 4 & $18.4 \pm 0.9$ & $<0.001$ \\
$\begin{array}{l}24 \mathrm{hr} \text { escape } \\
\text { peripheral }\end{array}$ & 4 & $17.1 \pm 1.4$ & - & & - \\
$\begin{array}{l}3 \mathrm{hr} \text { escape } \\
\text { low current }\end{array}$ & 4 & $16.0 \pm 1.0$ & 4 & $17.2 \pm 1.2$ & - \\
$\begin{array}{l}3 \text { hr escape } \\
\text { high current }\end{array}$ & 8 & $13.7 \pm 0.8$ & 10 & $19.8 \pm 1.0$ & $<0.01$ \\
\hline
\end{tabular}

${ }^{*}$ Group comparison Student $t$ test to control

$\doteqdot \mathrm{N}=$ number of animals

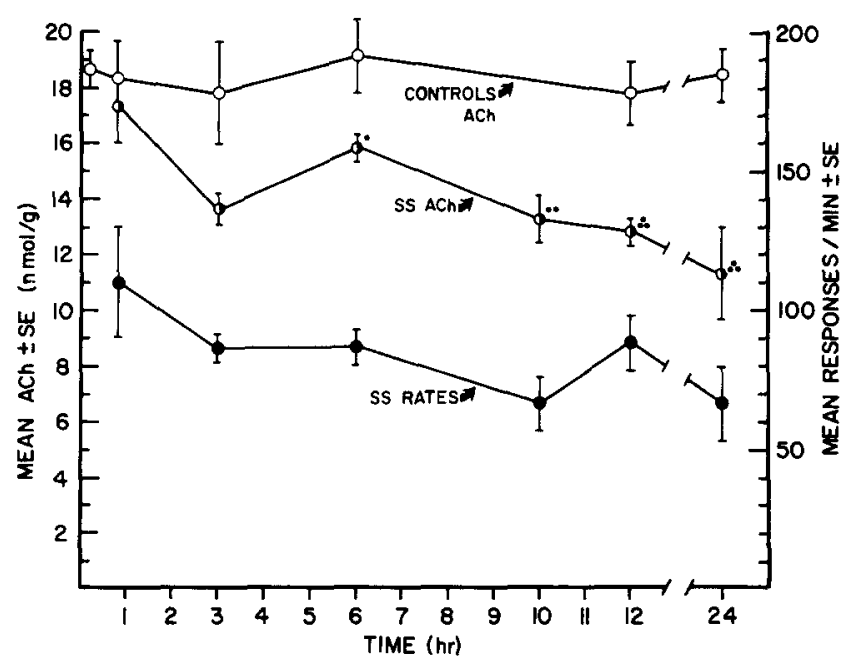

FIG. 1. Rat brain acetylcholine and response rate at various times during self-stimulation. Mean \pm S.E. data for brain ACh and mean response rates are given for groups of $6-20$ rats. The behavioral data represent the rates of responding for the period of time prior to sacrifice and the brain $\mathrm{ACh}$ data that at the time of sacrifice. Symbols are shown in this and Fig. 2 except ${ }^{*} p<0.05,{ }^{*} p<0.01$, $* * * p<0.001$ group comparison to control animals.

when the animals entered the dark cycle [23].

The effects of escape behavior on rat brain $\mathrm{ACh}$ at 3 and $24 \mathrm{hr}$ are given in Table 1. Control animals for this test had electrodes implanted in the midbrain tegmental region, and the motivational values of such stimulation had been determined during one training session. On the test day on which the animals were decapitated, they were not stimulated. The group of experimental animals for which stimulation in the midbrain was aversive was divided into two subgroups. One subgroup comprised all animals that required relatively intense stimulation $(50 \mu \mathrm{A})$ to maintain steady escape responding; the other subgroup required moderate to low intensities of stimulation to maintain high response rates to escape the aversive stimulation for $6 \mathrm{sec}$. In general, brain ACh decreased during escape behavior, as it did during self-stimulation behavior, but with one significant difference. When the escape test lasted $3 \mathrm{hr}$, the decrease in brain $\mathrm{ACh}$ was larger in the group receiving intense aversive stimulation than in the group receiving low to moderate aversive stimulation. Thus, for this test period the current intensity appeared to be an important factor determining brain content of $\mathrm{ACh}$. There was no difference between the two groups when the test period was $24 \mathrm{hr}$. This may have been related to the fact that after a session of such prolonged duration the levels of brain ACh were already very low and much more than a simple difference in current intensities could have been required to cause differences in brain $\mathrm{ACh}$. One group of test animals also received aversive stimulation, but the noxious stimuli were applied peripherally (foot shock) rather than centrally. It is interesting that in this group an escape session lasting $24 \mathrm{hr}$ caused no decrease in brain $\mathrm{ACh}$, while the same period of escape behavior for brain stimulation produced significant decreases.

The effects of different rates of either escape responding, or self-stimulation behavior on brain $\mathrm{ACh}$ are given in Table 2 . For this analysis the self-stimulators were divided into two subgroups: those that responded at rates of 60 responses or less per min in a session lasting $3 \mathrm{hr}$, and those that responded at rates above this. The escape animals were similarly subdivided. Here again, one subgroup comprised those animals whose rate of responding was more than 30 responses per min, and the other those animals with a lower rate. The higher rate of responding signified fewer aversive stimuli received, since a response signified the postponement for $6 \mathrm{sec}$ of the average stimuli. However, as was pointed out earlier (Methods section), these animals did not avoid. Hence, even the highest rates of responding signified that a certain number of aversive stimuli were taken. Apparently, at the frequency used in these tests, the number of stimuli taken either during approach or escape behavior made no significant difference in the levels of brain $\mathrm{ACh}$ when the test period was $3 \mathrm{hr}$. 
TABLE 2

EFFECTS OF BAR PRESSING ON RAT BRAIN ACh DURING SELF-STIMULATION AND ESCAPE BEHAVIOR

\begin{tabular}{|c|c|c|c|c|c|c|c|c|}
\hline \multirow[b]{2}{*}{ Behavior } & \multirow[b]{2}{*}{$N^{*}$} & \multirow{2}{*}{$\begin{array}{l}\text { Low Rates } \\
\text { resp } / \mathrm{min} \\
\text { mean } \pm \text { S.E. }\end{array}$} & \multirow[b]{2}{*}{$\mathrm{N}$} & \multirow{2}{*}{$\begin{array}{c}\text { High Rates } \\
\text { resp } / \text { min } \\
\text { mean } \pm \text { S.E. }\end{array}$} & \multirow[b]{2}{*}{$p$} & \multicolumn{2}{|c|}{$\begin{array}{c}\mathrm{ACh}(\mathrm{nmol} / \mathrm{g}) \\
\text { Mean } \pm \text { S.E. }\end{array}$} & \multirow[b]{2}{*}{$p$} \\
\hline & & & & & & Low responders & High responders & \\
\hline $\begin{array}{l}3 \mathrm{hr} \\
\text { Self-stimulation }\end{array}$ & 8 & $55.7 \pm 5.3$ & 12 & $103.1 \pm 5.5$ & $<0.001$ & $14.4 \pm 1.0$ & $13.2 \pm 0.6$ & NSt \\
\hline $\begin{array}{l}3 \mathrm{hr} \\
\text { Escape }\end{array}$ & 7 & $27.7 \pm 1.8$ & 7 & $40.1 \pm 2.2$ & $<0.001$ & $13.1 \pm 0.8$ & $14.6 \pm 0.7$ & NS \\
\hline
\end{tabular}

*Number of animals

$\dagger$ Not significant

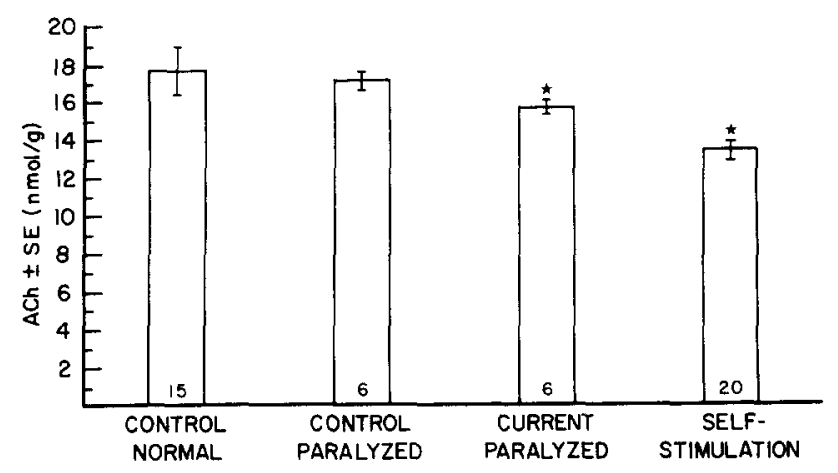

IIG. 2. Effects of electrical stimulation of posterior-lateral hypothalamus for $3 \mathrm{hr}$ in self-stimulating and paralyzed artificially ventilated rats. Groups of $6-20$ rats (see number within bar) were used. Rats were paralyzed with tubocurarine and artificially ventilated. The current paralyzed group was automatically stimulated at the approximate rate they normally would respond $(100 / \mathrm{min})$. Note that only the electrically stimulated animals showed a decrease in brain $\mathrm{ACh}(p<0.05)$ which was greater in the self-stimulators.

The decrease was similar for the self-stimulators at high rates and for those responding at low rates; the same was also true for the escapers.

Figure 2 summarizes the data on total brain $\mathrm{ACh}$ obtained in groups of rats paralyzed with $10 \mathrm{mg} / \mathrm{kg}$ of tubocurarine and respirated artificially throughout the duration of the experimental session that lasted $3 \mathrm{hr}$. One group of control animals had electrodes in the reinforcing region of the hypothalamus but received no stimulation during the session. However, the animals were paralyzed and thus were under stressful conditions. The group of test animals had electrodes in the posterior lateral hypothalamus and stimulation there was rewarding, as determined in previous training sessions when the subjects were not paralyzed. During the experimental session, the animals were stimulated automatically since they were paralyzed. The data show that total brain ACh decreased in this group of animals, as compared with the group of animals that were paralyzed but did not receive stimulation. However, the decrease in the test group was lower than in the group of animals that were allowed to self-stimulate during a similar period of $3 \mathrm{hr}$. In other words, although rewarding brain stimulation caused decreases in brain $\mathrm{ACh}$, it was larger in the group of animals in which freedom of movement permitted the self-application of the rewarding stimuli than in the group of animals in which the rewarding stimuli were applied automatically.

\section{DISCUSSION}

This study provides further evidence that $\mathrm{ACh}$, in addition to other putative brain neurotransmitters such as norepinephrine and 5-hydroxytryptamine, is functionally related to brain activity $[1,2,6,14,17]$. However, we could find no behavioral specificity for the fall in total brain $\mathrm{ACh}$. In both the self-stimulating and escaping animals, brain ACh levels gradually decreased the longer the rat continued to perform, regardless of whether the response rates were high or low. Although the overall rate of responding gradually declined over a $24 \mathrm{hr}$ period in self-stimulating rats, it should not be construed that decreased brain ACh was the cause. Scopolamine also reduces brain $\mathrm{ACh}$ but it does not always reduce responding until doses as large as $2 \mathrm{mg} / \mathrm{kg}$ or more are given [6]. It has been suggested [14] that the degree of emotionality associated with self-stimulation affects brain $\mathrm{ACh}$. This may be an important factor, but our own research indicates that the total period during which responding takes place, irrespective of the nature of the reinforcement, is also an important variable modifying the levels of brain $\mathrm{ACh}$. Furthermore, aversive brain stimulation, in these tests, was a more potent factor in reducing total brain $\mathrm{ACh}$ than peripheral electrical shock to the feet. Two other factors that determined brain levels during self-stimulation were freedom of motor movement and intensity of the centrally applied current.

A severe limitation to this study is that only total brain $\mathrm{ACh}$ levels were measured. One would expect marked regional differences depending upon the functional brain area involved. Moreover, total brain levels of any substance reflect only the relative rates of synthesis vs. destruction. It is widely agreed that turnover is a much more meaningful measure of functional activity. With respect to brain $\mathrm{ACh}$, indirect measures of turnover, for example, the use of blockers of ACh synthesis, suggest marked changes in turnover following the administration of psychotropic drugs in doses that do not alter total brain levels [7]. Hence, data which indicate that total brain $\mathrm{ACh}$ does not change must 
be interpreted with caution. Some other, more sensitive, measure such as $\mathrm{ACh}$ turnover may change dramatically. When total brain $\mathrm{ACh}$ is reduced, one can only conclude that synthesis is inadequate to keep up with demand.
Whether the synthesis of brain ACh is reduced over time, or whether the demand for more $\mathrm{ACh}$ is so great that normal synthesis cannot keep up is, of course, not known and must be the subject of further research.

\section{REFERENCES}

1. Aprison, M. H., T. Kariya, J. N. Hingten and M. Toru. Neurochemical correlates of behavior, changes in acetylcholine, norepinephrine, and 5-hydroxytryptamine concentrations in several discrete brain areas of the rat during behavioral excitation. J. Neurochem. 15: 1131-1139, 1968.

2. Bliss, E. L., V. B. Wilson and J. Zwanziger. Changes in brain norepinephrine in self stimulating and aversive animals. $J$. Psychiat. Res. 4: 59-63, 1966.

3. Crossland, J. Biologic estimation of acetylcholine methods. Meth. Med. Res. 9: 125-129, 1961.

4. Domino, E. F. Role of the central cholinergic system in wakefulness, fast wave sleep and "No-Go" behavior. In: The Present Status of Psychotropic Drugs, edited by A. Cerletti and F. J. Bove. Amsterdam: Excerpta Medica Foundation, 1969, pp. 273-277.

5. Domino, E. F. and M. E. Olds. Cholinergic inhibition of selfstimulation behavior. J. Pharmac. exp. Ther. 164: 202-211, 1968.

6. Domino, E. F. and M. E. Olds. Effects of d-amphetamine, scopolamine, chlordiazepoxide, and diphenylhydantoin on self-stimulation behavior and brain acetylcholine. Psychopharmacologia 23: 1-16, 1972.

7. Domino, E. F. and A. Wilson. Psychotropic drug influences on brain acetylcholine utilization. Psychopharmacologia 25: $291-298,1972$.

8. Feldberg, $W$. Present views on the mode of action of acetylcholine in the central nervous system. Physiol. Rev. 25: 596-642, 1972.

9. Friedman, A. H. and C. A. Walker. The acute toxicity of drug activity at cholinoceptive sites and twenty-four hour rhythms in brain acetylcholine. Arch. Tox. 29: 39-42, 1972.

10. Giarman, N. J. and G. Pepeu. Drug induced changes in brain acetylcholine. Br. J. Pharmac. 19: 226-234, 1962.

11. Goldberg, M. E., H. E. Johnson and J. B. Knaak. Inhibition of discrete avoidance behavior by three anticholinesterase agents. Psychopharmacologia 7: 72-76, 1965.

12. Hanin, I., R. Massarelli and E. Costa. Acetylcholine concentrations in rat brain: Diurnal oscillation. Science 170: $341-342,1970$.

13. Jung, O.H. and E.S. Boyd. Effects of cholinergic drugs on self-stimulation response rates in rats. Am. J. Physiol. 210: $432-434,1966$.

14. Krause, N., D. Samek, R. Sochanski and J. Hotowiecki. Investigations on the emotional states induced by the conditioned reflex path. Acta. physiol. pol. 15: 260-264, 1964.
15. Krieg, W. J.S. Accurate placement of minute lesions in the brain of the albino rat. $Q$ Bull. NWest. Univ. med. Sch. 20: 199-208, 1946.

16. Labrecque, G. and E. F. Domino. Daily fluctuation of total rat brain acetylcholine, its relation to the lighting regimen and the differential sensitivity to morphine. Archs Int. Pharmacodyn., in preparation, 1975 .

17. Markiewicz, L., W. Missiuro, Z. Brzezinska and A. Sawicka. Biochemical and morphological changes in brain tissue due to vibrations. Acta physiol. pol. 15: 427-432, 1964.

18. Olds, M. E. and E. F. Domino. Comparison of muscarinic and nicotinic cholinergic agonists in self-stimulation. $J$. Pharmac. exp. Ther. 166: 189-201, 1968.

19. Olds, M. E. and E.F. Domino. Differential effects of cholinergic agonists on self-stimulation and escape behavior. $J$. Pharmac. exp. Ther. 170: 157-167, 1969.

20. Olds, M. E. and J. Olds. Approach-avoidance analysis of rat diencephalon.J. comp. Neurol. 120: 259-295, 1963.

21. Rosecrans, J. A., A. T. Dren and E. F. Domino. Effects of physostigmine on rat brain acetylcholine, acetylcholinesterase and conditioned pole jumping. Int. J. Neuropharmac. 7: $127-134,1968$.

22. Richter, D. and J. Crossland. Variation in ACh content of the brain with physiological state. Am. J. Physiol. 159: 247-255, 1949.

23. Saito, Y. The circadian rhythm of brain ACh levels and motor activity in the rat. Life Sci. 10: 735-744, 1971.

24. Sidman, M. Avoidance conditioning with brief shock and no exteroceptive warning signal. Science 118: 157-158, 1953.

25. Stark, P. and E. S. Boyd. Effects of cholinergic drugs in hypothalamic self-stimulation response ratio of drugs. $A m . J$. Physiol. 205: $745-748,1963$.

26. Stone, W. E. Acetylcholine in the brain I. "Free," "bound" and total acetylcholine. Archs Biochem. Biophys. 59: $181-192,1955$.

27. Travis, R. P. and J. Olds. Two kinds of escape from midbrain stimulation. Am. Psychol. 14: 430, 1959.

28. Vaillant, G. E. Antagonism between physostigmine and atropine on the behavior of the pigeon. Naunyn-Schmiediergs Arch. exp. Path. Pharmak. 248: 406-416, 1964.

29. Vaillant, G. E. A comparison of antagonists of physostigmineinduced suppression of behavior. J. Pharmac. exp. Ther. 157: $636-648,1967$. 